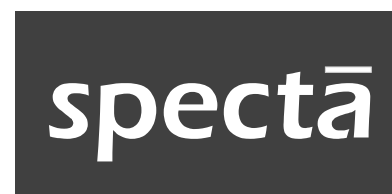

Journal of Photography,

Arts, and Media

\title{
SIMULACRA YOGYAKARTA DENGAN DRONE PHOTOGRAPHY
}

\author{
Kevin Andrian
}

Arti Wulandari*

Oscar Samaratungga**

Fakultas Seni Media Rekam, Institut Seni Indonesia (ISI)

Yogyakarta

Surel: artifajar@gmail.com

Volume 1 Nomor 2 ,

November 2017: 121-132

\begin{abstract}
Abstrak
Yogyakarta merupakan tempat yang pantas dan prayoga menjadi suri keindahan alam semesta. Tentu hal ini berkaitan dengan keistimewaan yang dimilikinya, baik yang tampak secara fisik maupun tidak. Namun demikian, seiring dengan berjalannya waktu keistimewaan tersebut kian pudar. Hal tersebut menimbulkan gejolak dalam diri dan ingin menyampaikannya melalui medium fotografi sebagai bentuk ungkapan ekspresi. Untuk itu diperlukan suatu cara yang berbeda karena Yogyakarta sudah terlalu sering diangkat sebagai objek fotografi. Drone photography dan simulacra merupakan kombinasi yang sesuai karena memiliki kekuatan menggoda siapapun untuk melihatnya. Drone photography memberikan ruang eksplorasi yang luas, sementara simulacra yang berarti replika dari realitas memberikan ruang eksperimentasi yang tidak terbatas. Keleluasaan penempatan kamera merupakan kekuatan utama dalam drone photography, namun demikian banyak pula kendala yang muncul. Hal tersebut menjadi tantangan dalam penciptaan karya dengan judul "Simulacra Yogyakarta dengan Drone Photography". Eksperimentasi yang dilakukan tidak terbatas pada hadirnya sebuah karya namun juga bagaimana sebuah karya disajikan untuk memberikan pengalaman yang lebih bagi penikmatnya. Menampilkan Yogyakarta dalam bentuk simulacra tidak hanya sekadar untuk menggoda, namun juga untuk memberikan cara yang berbeda untuk menikmati keistimewaan dan memahami permasalahan yang ada di Yogyakarta.
\end{abstract}

Kata Kunci : simulacra, Yogyakarta, drone photography

\begin{abstract}
Simulacra of Yogyakarta with Drone Photography. Yogyakarta is the proper place that deserves to be the the example of beauty the universe.

This may be related to the privilege owned by Yogyakarta, whether it appears physically or not. However, over time the privilege has started to fade. It creates an inner turmoil and it urges to convey it through the medium of photography as a form of expression. To do that may need a whole new different way because Yogyakarta has been too often appointed as a photographic object. Drone photography and simulacra are such an appropriate combination because both have the tempting power for anyone to see it. Drone photography provides a vast exploration space, while simulacra which means a replica of reality provides an unlimited space of experimentation. The flexibility of camera's placement is a major power in drone photography, but there are still many obstacles arising. It becomes a challenge in the creation of the photographic work entitled "Simulacra of Yogyakarta with Drone Photography". The experimentation is not limited to the presence of a work but also how a piece of work is presented to provide more experience for the audience. Featuring Yogyakarta in the form of simulacra does not only to tease but also to give a different way to enjoy its privilege and understand the problems existing in Yogyakarta.
\end{abstract}

Keyword: simulacra, Yogyakarta, drone photography

\footnotetext{
*Dosen di Program Studi Fotografi, Jurusan Fotografi, Fakultas Seni Media Rekam, ISI Yogyakarta

**Dosen di Program Studi Fotografi, Jurusan Fotografi, Fakultas Seni Media Rekam, ISI Yogyakarta
} 


\section{PENDAHULUAN}

Lima tahun sudah Daerah Istimewa Yogyakarta menjadi tempat singgah dalam menuntut ilmu, gelar istimewa yang dimiliki Yogyakarta karena adanya intangible dan tangible culture yang tertanam dalam dirinya sejak lama. Keistimewaan yang tidak kasat mata (intangible culture) berupa nilai budaya, pandangan hidup, moral, adat istiadat, dan aturan khusus sementara keistimewaan yang kasat mata (tangible culture) berupa tata kota, toponim, perkampungan, kesenian-kesenian, bangunan, dan benda-benda budaya fisik (Dewan Kebudayaan Kota Yogyakarta, 2006). Seiring dengan berjalannya waktu keistimewaan tersebut kian tergerus, Yogyakarta kini bertransformasi menjadi kota metropolitan nan modern beserta permasalahan yang kian menggerus keistimewaan Yogyakarta.

Hal tersebut menimbulkan gejolak dalam diri dan ingin sekali di sampaikan dengan menggunakan media fotografi. Menurut Soedjono dalamn buku Pot-pourri Fotografi,

"Sebuah karya yang dirancang dengan konsep tertentu dengan memiliki objek foto yang terpilih dan yang diproses dan dihadirkan bagi kepentingan si pemotretnya sebagai luahan ekspresi artistik dirinya maka karya tersebut bisa menjadi karya fotografi ekspresi (2007:40)"

Yogyakarta sudah terlalu sering diangkat sebagai objek fotografi, maka dibutuhkan sebuah cara yang berbeda untuk menciptakan sebuah karya yang menarik dan berbeda, maka dari itu fotografi udara dengan menggunakan drone dan simulacra dipilih. Pemandangan dari udara menjadi menarik karena menampilkan sudut yang tidak biasa, yang kini umum dipakai adalah drone yaitu pesawat tanpa awak yang dikendalikan dari jarak jauh dengan menggunakan komputer atau remote control serta dilengkapi oleh kamera (Cheng, 2015:9-10). Sesaat setelah drone meninggalkan gravitasi, visual pilot sudah berada di ruang tiga dimensi, terbang bebas secara virtual dan menjelajah bebas tanpa batasan, hal tersebut yang menjadi kekuatan utama teknik fotografi udara dengan menggunakan drone. Penciptaan karya ini tidak hanya sekadar eksplorasi dengan drone namun juga melibatkan eksperimetasi untuk menciptakan visual imajinasi dengan menggunakan teori simulacra. Plato menyampaikan bahwa simulacra/simulacrum adalah replika dari realitas yang tidak sempurna, replika dari dunia yang sempurna, simulacra/simulacrum bukanlah salinan, ada perbedaan yang signifikan antara keduanya, jika salinan merupakan citra yang dikaruniai oleh kemiripan, maka simulacra adalah citra tanpa kemiripan (Deluze \& Krauss, 1983:47-48).

Kombinasi antara drone photography dan simulacra memunculkan ruang eksplorasi dan eksperimentasi yang sangat luas. Karya yang dihasilkan memiliki kekuatan untuk menggoda/menarik perhatian, tidak hanya sekadar menarik namun memberikan cara yang berbeda untuk menikmati keistimewaan dan permasalahan, hal tersebut yang menjadi dasar penciptaan karya dengan judul Simulacra Yogyakarta dengan Drone Photography.

Berdasaran uraian tersebut, perumusan masalah dalam penciptaan karya dengan judul "Simulacra Yogyakarta dengan Drone Photography" antara lain sebagai berikut:

1. Bagaimana mengeksplorasi Yogyakarta dengan drone photography?

2. Bagamana menciptakan simulacra Yogyakarta melalui reproduksi dan eksperimentasi dalam bentuk visual imajinasi melalui fotografi ekspresi?

Tujuan dari penciptaan karya dengan judul "Simulacra Yogyakarta dengan Drone Photography" adalah untuk (1) mengeksplorasi 
Yogyakarta dengan drone photography, dan (2) menciptakan simulacra Yogyakarta melalui reproduksi dan eksperimentasi dalam bentuk visual imajinasi sebagai bentuk ungkapan ekspresi. Manfaat yang diharapkan adalah (1)menambah wawasan dalam bidang fotografi dengan teknik drone photography dan (2) menambah keragaman dalam penciptaan karya seni dengan memanfaatkan drone untuk kebutuhan fotografi udara.

\section{Ide Dan Konsep Perwujudan}

Latar belakang timbulnya penciptaan karya ini didasari oleh pengalaman pribadi selama 5 tahun tinggal di Yogyakarta, Daerah Istimewa Yogyakarta menyandang gelar istimewa bukan tanpa alasan. Keistimewaan yang tercermin dalam namanya Ngayogyakarta Hadiningrat yang berarti tempat yang pantas dan prayoga yang menjadi suri keindahan alam semesta Tanah harapan bagi pendatang yang ingin bergabung dan membangun masa depan (Dewan Kebudayaan Kota Yogyakarta, 2016:5). Namun seiring dengan perkembangan jaman keistimewaan itu dipertanyakan kembali, karena banyak yang datang dan hilang. Kini Yogyakarta justru menjadi daerah abu-abu di mana semua serba 'kabur' atau 'dikaburkan'. Sederet permasalahan membelit Yogyakarta mulai dari pembangunan yang berlebihan, sampah visual, kemacetan, serta perubahan perilaku manusia yang bertempat tinggal di dalamnya. Hal tersebut menimbulkan gejolak dalam diri dan ingin diungkapkan sebagai bentuk dari ungkapan ekspresi. Namun ada suatu tantangan yaitu Yogyakarta sudah terlalu sering diangkat sebagai objek fotografi, maka dibutuhkan sebuah cara agar cerita yang disampaikan dapat menarik, maka dari itu menampilkan cerita Yogyakarta dari udara dalam bentuk simulacra dipilih.

Kelebihan dari penggunaan drone untuk fotografi udara adalah keleluasaan penempatan kamera, sementara simulacra yang berarti replika/tiruan memberikan keleluasaan dalam menciptakan karya sejauh imajinasi memungkinkan dengan memanfaatkan berbagai macam teori maupun teknik antara lain; mimesis, deformasi, perspektif, panorama, warna, montase, hingga instalasi karya. Kombinasi keduanya memberikan ruang eksplorasi dan eksperimentasi yang luas dalam penciptaan sebuah karya sebagai bentuk ungkapan ekspresi. Menampilkan sesuatu dari sudut dan bentuk yang tidak biasa ditujukan untuk menarik/menggoda, tidak hanya itu namun juga memberikan cara yang berbeda dalam menikmati keistimewaan dan permasalahan yang terjadi di Yogyakarta.

\section{Mimesis, Simulacra, dan Deformasi}

Mimesis berasal dari bahasa Yunani yang berarti tiruan. Mimesis merupakan upaya untuk menciptakan sebuah imitasi atau representasi. Menurut Plato, mimesis adalah imitasi, representasi, ekspresi, emulasi, transformasi, penciptaan kesamaan, produksi penampilan, dan ilusi. (Gebauer and Wulf, 1995:25-31). Ruby dalam buku Picturing culture: exploration of film and anthropology bahwa mimesis adalah salinan yang akurat atau representasi sebenarnya dari kenyataan yang bisa diabadikan. Seperti halnya sifat objektif dari fotografi yaitu memberikan kualitas dan kredibilitas yang tidak dapat ditemui pada pembuatan gambar lainnya, dalam artian ketika seseorang melihat sebuah karya fotografi, ia "dipaksa" untuk menerima sebuah reproduksi dari objek sebagai suatu kenyataan padahal karya tersebut merupakan sebuah representasi. sesuatu yang diciptakan di ruang dan waktu yang berbeda (2000:269270).

Simulacra berasal dari bahasa Latin simulare yang berarti kemiripan atau kesamaan, istilah ini pertama kali digunakan oleh Plato, menurut Plato simulacra/simulacrum adalah replika dari realitas yang tidak sempurna, 
replika dari dunia yang sempurna. Simulacra bukanlah salinan (copy), ada perbedaan antar kedua hal tersebut, jika salinan (copy) adalah citra yang dikaruniai dengan kemiripan. Simulacra adalah citra tanpa kemiripan ( Deluze\& Krauss, 1983:47-48). Simulacra adalah salinan dari salinan, sesuatu yang tidak disandingkan dengan realitas. Soedjono dalam buku Pot-Pourri Fotografi menjelaskan bahwa kini fotografi tidak sekadar "taking picture of reality" namun berkembang menjadi "creating picture of reality plus artificiality", rekayasa sejauh imajinasi memungkinkan untuk menciptakan karya yang bernilai estetis kreatif (2007:17).

Deformasi adalah faktor kunci dalam menciptakan/menghadirkan sebuah persepsi mendalam karena sifatnya mengurangi kesederhanaan dan meningkatkan ketegangan di bidang visual, tidak hanya sekadar perubahan bentuk. Deformasi menunjukkan bahwa ada beberapa dorongan mekanis atau tarik ulur yang diterapkan pada suatu objek, contohnya; seolah-olah dikompres, ditarik, atau dibengkokkan. Hal tersebut berarti bentuk dari suatu objek sudah mengalami perubahan dari aslinya( Arnheim, 1974:259).

\section{Fotografi Udara dan Drone Photography}

Fotografi udara adalah "Pengambilan foto dari sudut yang tinggi, biasanya tidak dipasang pada suatu struktur di darat" (Papilaya, 2015). Sejarah fotografi udara dimulai pada tahun 1858 ketika seorang balloonist dan fotografer berkebangsaan Perancis, Gaspard-Felix Tournachon atau biasa dikenal dengan Nadar, muncul dengan ide 'gila' untuk memetakan Perancis dari udara. Sayangnya usaha foto udara pertama tersebut tidak berjalan sesuai rencana karena kendala teknis yang menyebabkan tidak ada karya yang selamat pada ekpedisi dan bisa dinikmati saat ini (Hawkes \& McConnel, 2003:10-11). Usaha selanjutnya dilanjutkan oleh James Wallace Black pada tahun 1860, dan karyanya yang berjudul "Boston, as the eagle and wild goose see it," (1860) dikenal sebagai foto udara paling awal yang masih selamat (Stichelbaud 2009:2). Seiring dengan berjalannya waktu, media untuk membawa fotografi udara kian berkembang dan makin umum dipakai adalah drone. Drone berarti menciptakan suara dengung rendah secara kontinyu, dalam Bahasa inggris lama "draen" berarti lebah jantan (Oxford Online). Drone adalah istilah aeronautika yang mengacu pada pesawat tanpa awak yang dikendalikan melalui komputer dan remote control atau Unmaned Aerial Vehicle (UAV). Istilah tersebut muncul pada tahun 1930-an saat pesawat tanpa awak digunakan sebagai target latihan, pesawat tanpa awak tersebut diistilahkan sebagai lebah dan pengendalinya sebagai ratu lebah. Pengambilan gambar dari udara menggunakan drone memberikan tampilan visual baru dan menarik, terbukanya dimensi vertikal dalam pergerakan dan penempatan kamera membuka ruang eksplorasi yang luas. Pengoperasiannya pilot harus mengetahui peraturan yang berlaku, tiap negara memiliki peraturan yang berbeda, di Indonesia sendiri regulasi yang berlaku mengacu pada Peraturan Mentri (PM), antara lain; PM 163/2015 ,PM 180/2015, serta PM 47/2016

\section{AIRCRAFT FLIGHT PATH MAP YOGYAKARTA}

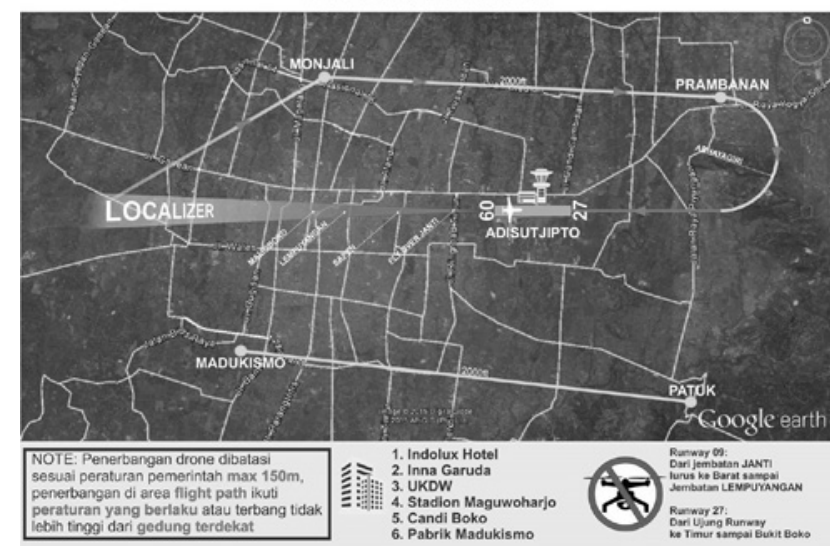

Gambar. 1 Jalur Penerbangan di Yogyakarta (Sumber: Komunitas Multirotor Jogja) 


\section{INSTALASI KARYA}

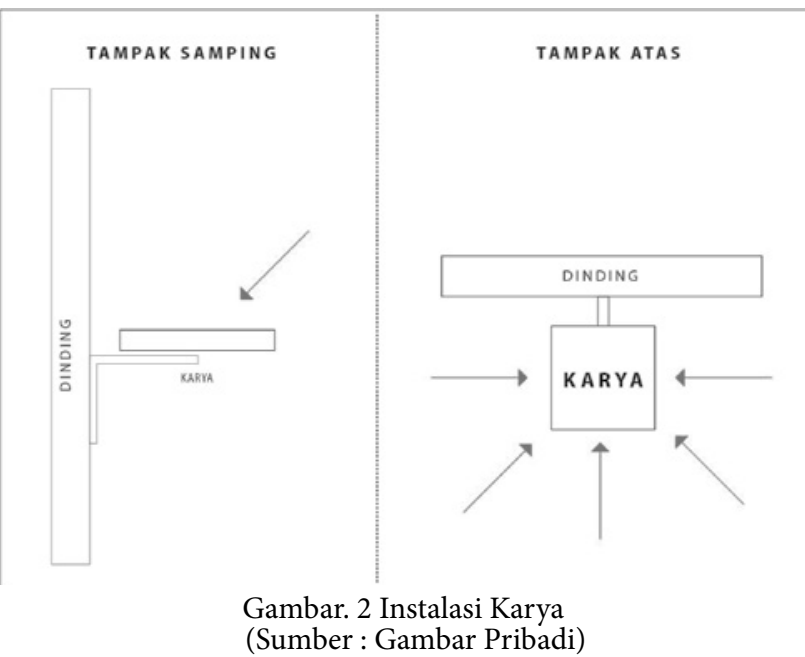

Mayoritas karya berada dalam posisi horizontal agar pengunjung pameran merasakan pengalaman yang sama seperti melihat dari udara, selain itu pemasangan karya dalam sudut horizontal juga membuka peluang karya bisa dilihat dari berbagai arah yang berbeda.

\section{METODE PENCIPTAN KARYA}

Tahap idea tau eksplorasi meliputi penetapan ide, tema, dan judul karya. Observasi dilakukan untuk mengembakan ide serta mendapatkan pravisualisasi dari karya bisa dilakukan secara langsung dengan mendatangi lokasi maupun secara digital dengan bantuan perangkat lunak Google Earth. Hal yang dilakukan pada saat observasi adalah penerbangan awal dan pengambilan gambar sekeliling lokasi, setelahnya dilakukan pencatatan rintangan seperti kabel, pohon, atau hal yang dapat menghambat serta lokasi lepas landas dan mendarat drone.

Tahap beikutnya yaitu konsep atau eksperimentasi, yaitu pembuatan sketsa berdasarakan pravisualisasi yang didapatkan. Objek dan kejadian yang akan direproduksi lalu dituangkan dalam coretan tangan, imajinasi tidak terbatas namun fotografer harus bisa mengukur kemampuan dalam mewujudkannya dalam media fotografi.

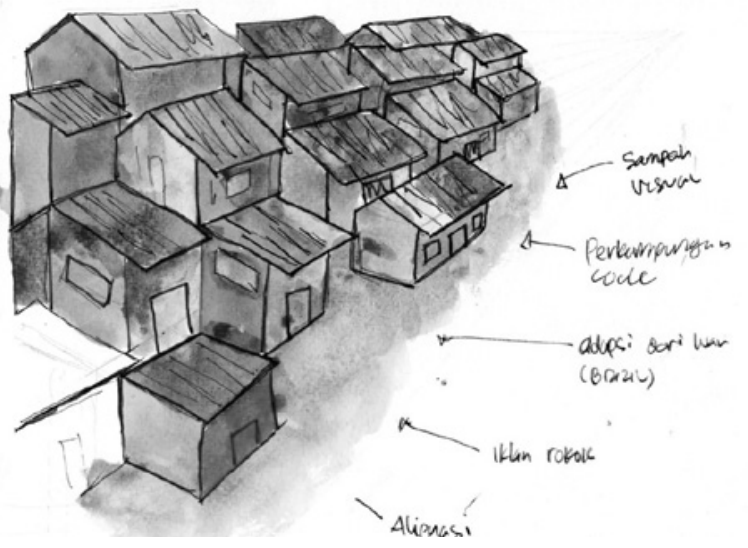

Gambar. 3Rancangan Visual (Sumber: Dokumentasi Pribadi)

Sketsa sangat membantu dalam proses penciptaan karya karena apapun yang terlihat dari udara begitu berbeda sekaligus menarik, maka diperlukan panduan dalam pengambilan gambar, hal ini berkaitan dengan efisiensi karena drone memiliki batasan waktu terbang.

Sketsa dibuat setelah mendapatkan pravisualisasi saat observasi, karena 3DR SOLO hanya mampu terbang 10 menit per baterai,maka sketsa sangat bermanfaat dalam pengerjaan karya karena menyangkut efisiensi dan efektivitas. Sketsa bisa berupa gambar yang mendekati karya akhir atau bisa berupa pengembangan, hal ini bergantung pada temuan-temuan yang didapatkan.

Setelah mendapatkan pravisualisasi dan membuat sketsa, langkah selanjutnya adalah eksekusi di lapangan. Teknik yang digunakan dalam penciptaan karya Simulacra Yogyakarta dengan Drone Photography adalah pengambilan gambar dari berbagai sudut dan ketinggian berbeda, penggabungan elemen gambar untuk menghasilkan suatu imaji baru serta reproduksi dari suatu kejadian serta pengambilan gambar dari jarak dekat. Dalam fotografi udara terdapat dua sudut pandang kamera yaitu menyamping/serong (oblique) dan tegak lurus (straight down/vertical). Sudut pandang oblique mengasilkan imaji dengan dimensi, sementara sudut pandang vertical menghasilkan imaji datar. Setelah pemotretan file foto di transfer ke laptop untuk 
dimasukkan ke bank foto dan selanjutnya dilakukan proses editinguntuk menciptakan sebentuk simulacra, beberapa diantaranya adalah panorama udara 360 derajat dengan proyeksi spherical dan rectilinear, montase, permainan warna, distorsi, semua disesuaikan dengan apa yang sudah tertuang di dalam sketsa/rancangan visual.

\section{TINJAUAN KARYA}

\section{Ade Dani Setiawan - Yogyakarta dari Udara}

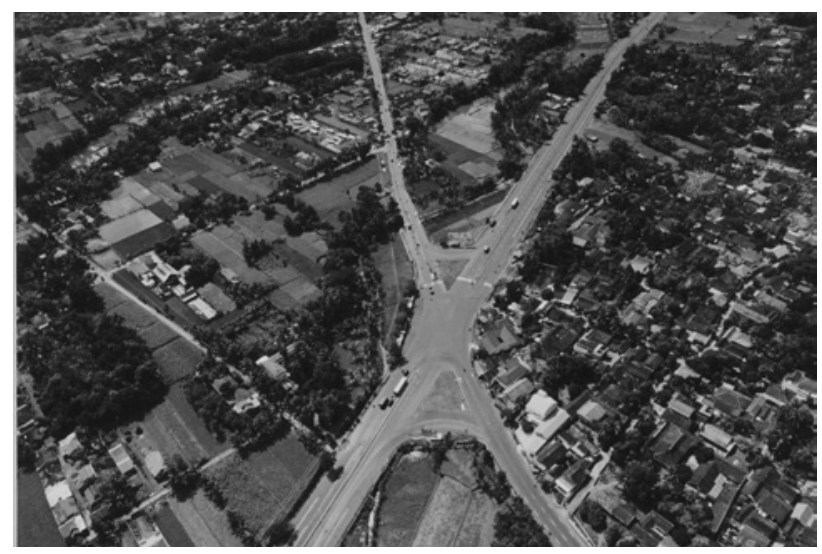

Gambar. 4 Huruf X

(Sumber: Skripsi - Setiawan, 1999)

Ade Dani Setiawan adalah alumni Jurusan Fotografi, Fakultas Seni Media Rekam, Institut Seni Indonesia Yogyakarta. Tugas akhirnya di tahun 1999 yang berjudul "Yogyakarta dari Udara sebagai Sumber Inspirasi Pernciptaan Karya Seni Fotografi". Dia mencoba untuk menvisualisasikan bentuk geometris yang ditemui pada permukaan bumi serta bentuk-bentuk yang dibuat manusia. Dalam mengambil foto dari udara, Ade menggunakan helikopter NBell-412 dan trike serta kamera analog. Pada karyanya Ade lebih berfokus mengeksplorasi sudut pengambilan gambar sebagai bentuk ungkapan ekspresi.Walau bukan diambil menggunakan drone, karya ade dipakai sebagai acuan karena mengangkat hal yang sama yaitu Yogyakarta dari udara, dan sekaligus pembanding antara fotografi udara menggunakan pesawat atau helikopter dan menggunakan drone

\section{Aydın Büyüktaş - Flatland}

Terinspirasi dari novel terbitan 1884 dengan judul Flatland yang menggambarkan sebuah dunia

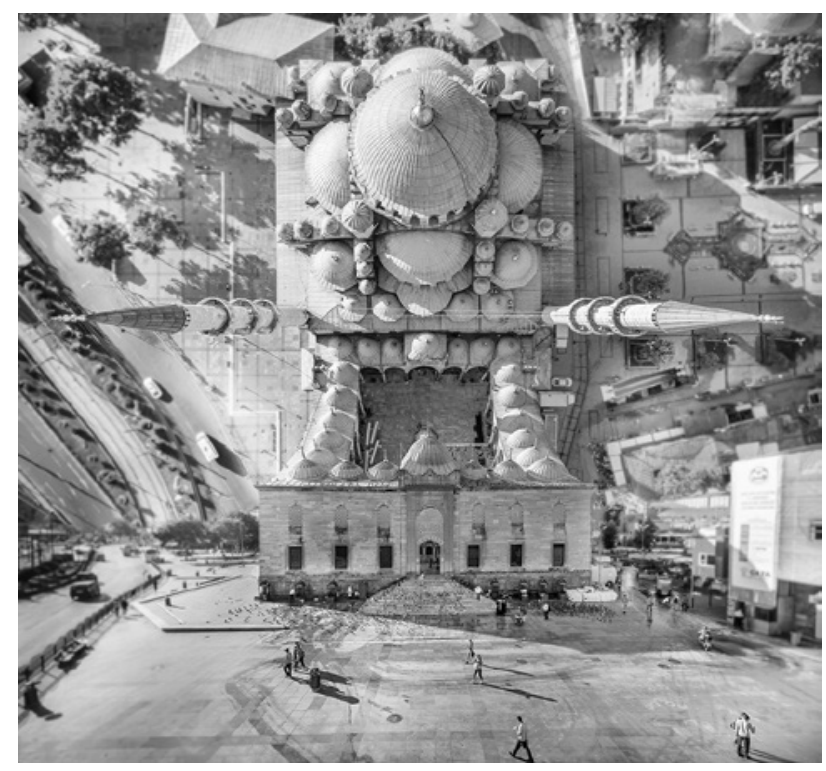

Gambar. 5 Yeni Cami (Flatland - 2016)

(Sumber : http://www.aydinbuyuktas.com/wpcontent/uploads/2016/09/New Mosque-1024x956. jpg diakses pada 3 Maret 2017 pukul 09.00 WIB )

dua dimensi yang ditempati oleh tokoh-tokoh geometis, fotografer Turki dan seniman digital Aydın Büyüktaş mengubah jalanan Istanbul terbalik dan tampak melengkung. Sesuatu yang sederhana namun sangat menarik untuk dilihat, dalam seri yang diberi judul Flatland, Aydin menggabungkan beberapa gambar dari sudut dan ketinggian yang berbeda yang menghasilkan karya dengan ilusi optik.

Penciptaan karyanya cukup rumit karena melibatkan penggabungan perspektif dan penggabungan banyak gambar, semakin banyak gambar yang digabungkan maka efek lengkung yang dihasilkan akan lebih halus. Buyuktas memanfaatkan garis sebagai pemandu dalam menyambungkan gambar, contohnya adalah garis pada bangunan dan jalan. Hal yang diacu dari karya Flatland yang diciptakan Aydin Buyuktas dalam penciptaan dengan judul "Simulacra Yogyakarta dengan Drone Photography" adalah permainan perspektif dan menggabungan berbagai sudut pandang dan ketinggian dalam menampilkan objek.

\section{Sebastien Staub - OCN}

Seringkali muncul pertanyaan "seberapa tinggi drone bisa terbang?" Sebastien Staub fotografer asal Swiss berkreasi dengan karya fotografi udara 


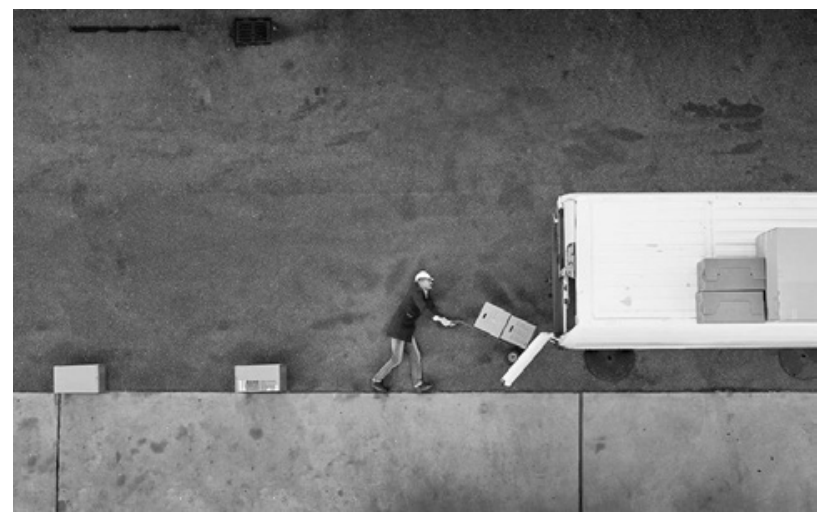

Gambar 6. OCN (2016)

(Sumber : http://sebastienstaub.com/projects/\#/ocn/ diakses pada 3 Maret 2017 pukul 10.00 WIB)

(lihat gambar 6) tidak selalu soal mengambil foto udara dari posisi yang sangat tinggi, imaji vertikal dari jarak dekat juga bisa sangat menarik.

Bekerjasama dengan Office de la Circulation et de la Navigation - OCN (organisasi yang bertanggungjawab untuk mengelola pendaftaran mobil di Swiss), Staub menciptakan fotografi udara jarak dekat yang ringan di sertai sedikit humor. Karya Staub begitu menarik karena ia hanya memanfaatkan satu sudut pandang (vertikal) dan membuat objeknya (manusia) untuk mengikuti sudut pandang tersebut sehingga menghasilkan karya dengan ilusi optik.Bagian yang diacu dari karya OCN ciptaan Sebastien Staub adalah pemanfaatan sudut pandang vertikal dan pemanfaatan drone untuk mengambil gambar dari jarak yang dekat dan pemanfaatan sudut pandang vertikal.

\section{PEMBAHASAN}

Menurut sejarah, daerah Krapyak merupakan sebuah hutan kecil yang di dalamnya masih terdapat banyak hewan liar seperti kijang dan rusa (lihat gambar 7), daerah ini menjadi tempat pilihan bagi para raja untuk berburu, untuk mendukung kegiatan tersebut maka dibangunlah Panggung Krapyak sebagai tempat beristirahat yang nyaman sekaligus sebagai tempat berlindung dari serangan hewan buas. Namun kini semua hanya tinggal cerita, struktur beton bercampur besi yang beradu tinggi, Panggung Krapyak dan hutannya tenggelam dalam lautan beton. Hal tersebut yang menjadi dasar dalam penciptaan karya dengan judul "Hutan Krapyak"

Teknik dalam penciptaan karya ini adalah panorama udara 360 derajat yang ditampilkan dalam bentuk proyeksi planar di mana hanya imaji pada bagian tengah yang diproyeksikan, sementara bagian lain direproyeksi sehingga menghasilkan efek distorsi, selain itu efek yang timbul adalah ilusi ketinggian, pengambilan gambar dilakukan dari ketinggian 15 meter namun seolah diambil dari sudut yang sangat tinggi, hal ini juga sekaligus dapat mengatasi kendala batas ketinggian dalam pengoperasian drone. Teknik lain yang digunakan adalah twirl dan selective color pada perangkat lunak pengolah gambar. Twirl digunakan untuk menciptakan efek Panggung Krapyak yang tenggelam atau tertelan, sementara selective color digunakan untuk memisahkan pohon dan struktur beton. Karya ini merupakan

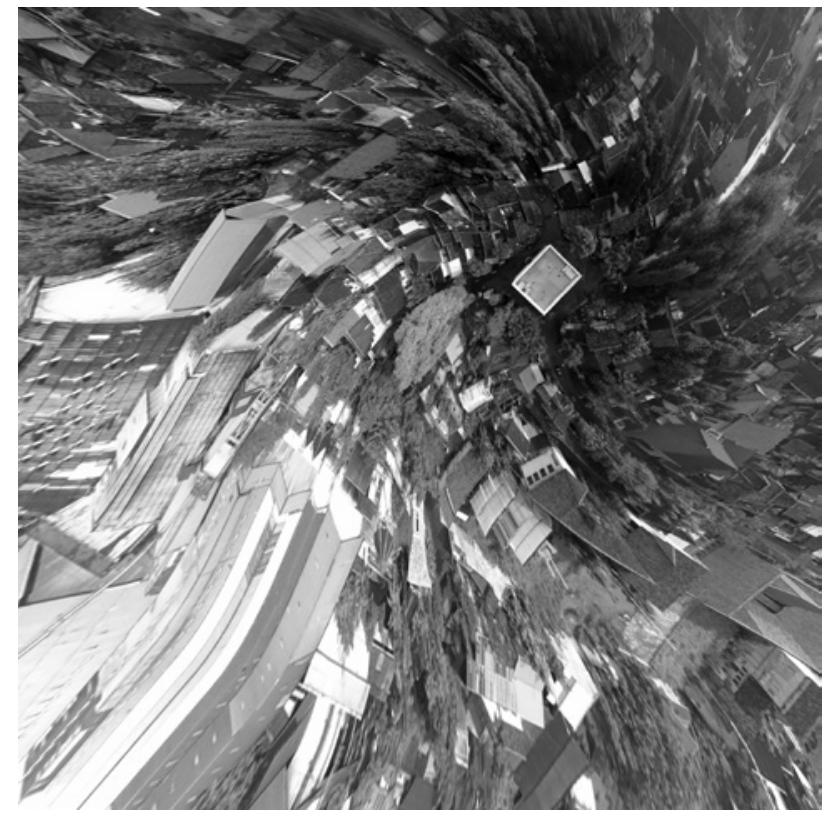

Gambar 7. "Hutan Krapyak", Kevin Andrian, $65 \times 65 \mathrm{~cm}$, Cetak pada media Luster Doff (2017) 
kombinasi antara sudut tegak lurus dan format persegi dengan komposisi radial. Hal ini memungkinkan foto dapat diputar dan dilihat dari berbagai sudut yang berbeda.

Yogyakarta yang ideal merupakan hal utama yang ingin ditampilkan dalam karya dengan judul "Praja Cihna" (lihat gambar 8), ideal dalam artian Yogyakarya yang tegas kuat, dan berani seperti burung garuda, Yogyakarta yang hijau, sejuk, dan menyegarkan mata. Yogyakarta sebagai rumah tempat berlindung bagi mereka yang membutuhkan. Hal tersebut yang harusnya tercermin di halaman depan Keraton Yogyakarta. Praja Cihna merupakan lambang Keraton Yogyakarta, Praja berarti abdi negara sementara Cihna berarti sifat sejati. Secara harfiah Praja Cihna berarti sifat sejati seorang abdi negara. Praja Cihna terdiri dari beberapa bagian antara lain; aksara jawa 'Ha' dan 'Ba' singkatan dari Hamengku Buwono yang berarti mengayomi bumi, mahkota yang berarti kepemimpinan, sayap garuda yang melambangkan keagungan serta kewibawaan keraton yang tegas, bunga padma yang melambangkan kebijaksanaan dan kekuatan prinsip, tumbuhan sulur yang merambat melambangkan kejayaan dan kemulian budaya bangsa nusantara, serta

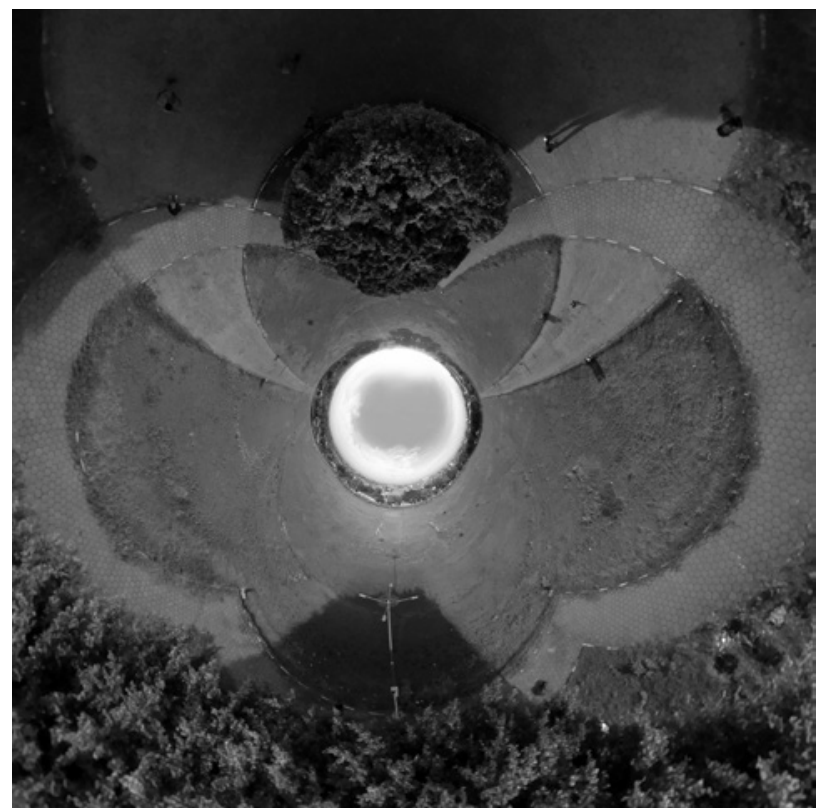

Gambar 8. "Praja Cihna", Kevin Andrian, 84x84cm, Luster Doff (2017) warna emas yang melambangkan keluhuran dan merah yang melambangkan keberanian.

Teknik yang digunakan adalah panorama udara 360 derajat dengan proyeksi spherical melalui perangkat lunak pengolah panorama. Karya ini merupakan temuan paling menarik, karena ketika foto panorama diambil tepat di atas dua beringin kembar Alun-alun Utara dan ditampilkan dengan proyeksi spherical maka akan muncul bentuk yang menyerupai simbol Praja Cihna, hal yang lebih menarik lagi gambaran tersebut hanya bisa muncul di halaman depan Keraton Yogyakarta, tidak bisa ditampilkan dari tempat lain. Tidak ada kendala yang berarti ketika melangsungkan penciptaan karya, hanya masalah baterai yang tiba-tiba drop ketika berada di udara, namun permasalahan tersebut diatasi dengan mengganti dengan baterai baru.

Yogyakarta sedang memasuki fase "reklamasi udara" (lihat gambar 9), fase di mana membangun ke samping sudah tidak memungkinkan lagi. Jika ada yang bilang bahwa lahan di Yogyakarta itu masih luas, apakah benar demikian? Lahan kosong miliki publik atau hanya sebentuk lahan yang menunggu waktu untuk dibangun? Membangun dan menghancurkan merupakan siklus yang berlangsung terus menerus hingga tidak ada lagi lahan yang tersisa. Hal ini yang coba digambarkan dalam karya dengan judul "Reklamasi Udara", yaitu ketika Yogyakarta yang dipenuhi struktur geometris ditampilkan meruncing ke udara.

Teknik dalam penciptaan karya ini adalah dengan menggunakan panorama udara 360 derajat, proyeksi planar. Namun terdapat kendala karena Dagen dalam foto tersebut termasuk jalur pesawat maka drone tidak diperkenankan terbang lebih tinggi dari pada gedung terdekat. Dalam konsep, apa yang ingin ditampilkan adalah gambaran yang luas, solusinya dengan teknik 


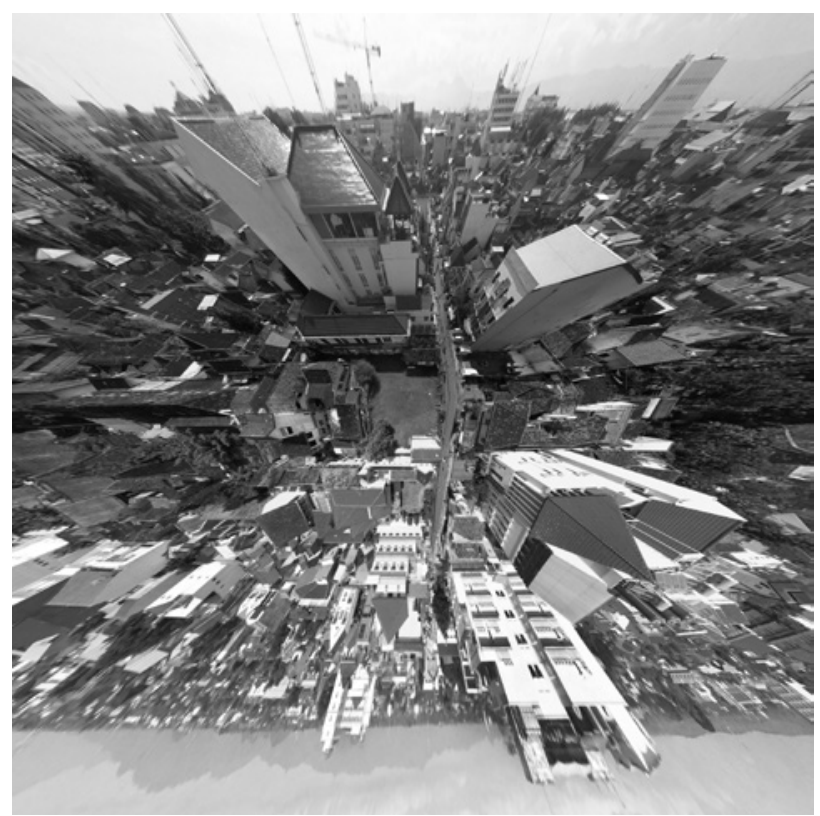

Gambar 9. "Reklamasi Udara”, Kevin Andrian, 65x65cm, Luster Doff (2017)

penggabungan dua proyeksi planar dari arah yang berlawanan, selain menampilkan imaji yang luas, penggabungan dua perspektif dari arah berlawanan ini juga menciptakan ilusi optik dimana objek terlihat seperti terlipat dan bangunan yang tinggi lebih terlihat tinggi. Sementara itu permainan selective color dilakukan untuk lebih menonjolkan lahan kecil yang masih tersisa di antara para pencakar langit serta memusatkan perhatian pada bentuk gedung. Karya ini menggunakan komposisi radial di mana pusatnya berada di tengah dan dapat dilihat dari berbagai sisi berbeda.

Yogyakarta pernah menjadi tempat yang ramah bagi pesepeda (lihat gambar 10), namun kini moda transportasi ini mulai ditinggalkan, bahkan ruang tunggunya pun sudah habis diserobot pengguna kendaraan lain yang mengakibatkan pengguna sepeda makin terusir. Hal ini coba digambarkan dalam karya dengan judul "Ruang Tunggu Pesepeda". Dalam realitas tentu saja tidak ada persepeda yang berbaring di ruang tunggu tersebut, yang dimaksud dalam karya ini adalah ruang tunggu tersebut bukan hanya tulisan dan gambar sepeda saja, namun

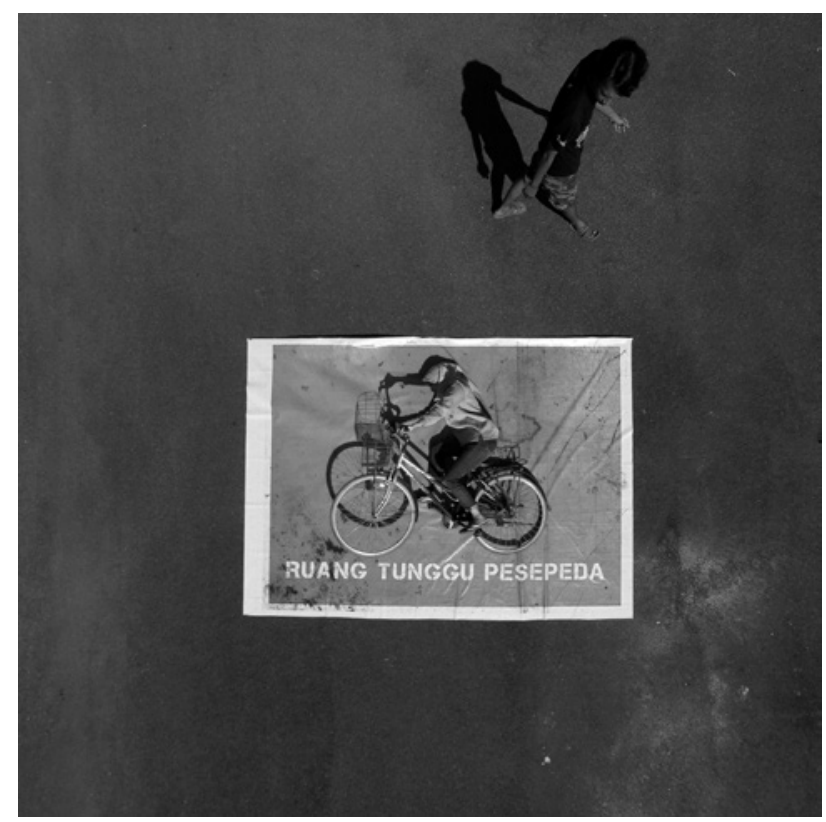

Gambar 10. "Ruang Tunggu Pesepeda", Kevin Andrian, 65x65cm, media Luster Doff (2017)

merupakan ruang tunggu pengguna jalan lain (pesepeda), ada hak pengguna jalanan di sana, tentu harapannya adalah munculnya kesadaran untuk berbagi.

Teknik dalam penciptaan karya ini adalah fotografi udara jarak dekat dan sudut pengambilan nol derajat/tegak lurus yang diacu dari karya Sebastien Staub, hal utama yang menjadi kendala adalah terbang cukup dekat diatas manusia, untuk memotret langsung di ruang tunggu sepeda asli cukup riskan, selain dapat mengganggu konsentrasi pengguna jalan, terbang rendah di ruang publik dapat menimbulkan potensi masalah jika terjadi sesuatu dengan wahana drone, hal ini diatasi dengan cara membuat simulasi dari ruang tunggu pesepeda di tempat lain. caranya ialah mencetak gambar ruang tunggu pesepeda berukuran $3 \times 2$ meter, selanjutnya pemotretan dilakukan di ruang yang terkontrol. Namun demikian, potensi terhdap bencana tetap ada, maka untuk mengatasi hal tersebut, pilot juga berada sangat dekat dengan talent, hal ini dilakukan jika terjadi apa-apa pilot dapat segera "pasang badan" untuk melindungi orang disekitar. 


\section{SIMPULAN}

Penggunaan drone untuk keperluan fotografi udara memberikan kebebasan yang luar biasa dalam penempatan kamera, hal ini berarti ruang yang hampir tidak terbatas untuk mengekplorasi berbagai sudut yang mungkin sulit dijangkau ketika menggunakan medium fotografi lainnya. Hal tersebut yang menjadikan karya dengan drone photography tampil berbeda karena menampilkan sesuatu dari sudut yang tidak biasa. Sementara itu Simulacra tercipta dari berbagai teknik fotografi seperti penggunaan format persegi, montase, distorsi, panorama, serta permainan warna memberikan ruang eksperimen yang tidak terbatas dalam penghadiran suatu karya, hal ini dikarenakan simulacra adalah salinan dari salinan, maka simulacra bisa secara langsung disandingkan dengan realitas yang ada seperti halnya sebuah salinan. Yogyakarta sudah terlalu sering diangkat sebagai objek dalam fotografi, maka diperlukan suatu cara yang berbeda, kombinasi antara simulacra dan drone photography dalam menampilkan Yogyakarta menjadikan karya ini memiliki kekuatan menarik atau menggoda orang untuk melihat.

Semua imaji yang digunakan dalam penciptaan karya dilakukan menggunakan drone, termasuk memotret benda-benda kecil seperti mainan gajah dan gambar pesawat, dalam prosesnya drone hanya terbang beberapa sentimeter dari permukaan tanah. Hal ini ditujukan untuk membuktikan keleluasaan penggunaan drone untuk kebutuhan fotografi sekaligus mematahkan pandangan mengenai drone yang hanya ditujukan untuk mengambil gambar dari ketinggian. Bicara soal ketinggian, drone memiliki batasan terbang, dalam peraturan yang berlaku maksimal 150 meter, namun dibeberapa tempat tertentu khusunya jalur pesawat, drone tidak diperkenankan terbang melebihi tinggi gedung terdekat, hal ini tentu menjadi kendala ketika ingin mendapatkan gambar yang luas, solusi yang didapatkan ialah dengan memanfaatkan fitur panorama, dengan demikian untuk mendapatkan imaji yang luas, drone tidak harus terbang sangat tinggi.

Cuaca menjadi tantangan utama, hal ini dikarenakan penciptaan karya ini sepenuhnya bergantung pada cahaya matahari serta kondisi cuaca pancaroba menjadikan penciptaan karya kian sulit, tidak jarang harus dilakukan beberapa kali pengambilan gambar di waktu yang berbeda untuk mendapatkan cahaya yang sesuai dengan keinginan. Tantangan lain adalah hal tidak terduga yang tiba-tiba muncul, seperti tali laying-layang atau burung. Baterai menjadi tantangan berikutnya, karena baterai drone yang digunakan dalam penciptaan karya ini hanya mampu bertahan sekitar 10 menit di udara, dengan demikian pilot harus pintarpintar memanfaatkan waktu terbang, hal ini tentu terbantu dengan pembuatan rancangan visual serta pravisualisasi. Kendala lain yang dihadapi adalah kualitas foto yang dihasilkan oleh GoPro tidak sebaik menggunakan kamera lain, hal ini berkaitan dengan sensor dan lensa yang digunakan.

Eksperimen tidak hanya terbatas pada bagaimana sebuah karya dihadirkan namun juga bagaimana sebuah karya disajikan, karya mayoritas karya disajikan pada posisi horizontal, hal ini merupakan replika "Pemandangan dari atas", tujuannya ialah memberikan pengalaman yang berbeda dalam menikmati karya serta membuka peluang sebuah karya fotografi dinikmati tidak hanya dari satu arah pandang namun dari berbagai arah pandang.

Eksplorasi dan eksperimen dalam pemanfaatan drone untuk fotografi sudah dilakukan semaksimal mungkin, namun demikian apa yang sudah dihasilkan masih dapat dikembangkan lagi karena masih terdapat banyak sekali potensi untuk menghadirkan sebuah karya yang berbeda dengan memanfaatkan 
drone. Tidak ada yang instan dalam penciptaan sebuah karya, walaupun secara hitam di atas putih karya ini ini dikerjakan dalam satu semester namun proses persiapannya seperti belajar mengendalikan drone memakan waktu hampir satu setengah tahun.

Selain sebagai bentuk ungkapan ekspresi, karya-karya ini juga diharapkan bisa menjadi dasar serta inspirasi dalam penciptaan karya khususnya fotografi udara dengan memanfaatkan drone.

Simulacra merupakan ruang tak terbatas dalam menciptakan sebuah karya, sejauh imajinasi memungkinkan serta kemampuan praksis untuk mewujudkannya, untuk mempermudah sebaiknya imajinasi tersebut dituangkan dahulu dalam bentuk coretan kasar/rancangan visual yang selanjutnya diolah untuk menjadi sebuah karya, hal ini berkaitan dengan efisiensi waktu. Udara merupakan dunia tiga dimensi yang cukup asing, tentu akan banyak sekali kendala yang dihadapi, sesuatu yang sudah diduga maupun tak terduga, namun semua itu bisa diatasi dengan memperbanyak jam terbang. Selain itu, bergabung dengan komunitas juga sangat membantu karena dari komunitas tersebut kita bisa mendapat ilmu-ilmu baru serta informasi yang bermanfaat.

Masih terdapat banyak potensi dalam penghadiran sebuah karya fotografi dengan memanfaatkan drone, namun karena keterbatasan waktu hal tersebut belum dapat terwujudkan, sebagai contoh, poros imajiner Yogyakarta masih belum lengkap, hal tersebut dapat dikembangkan lagi kedepannya. Seorang pilot drone dan seorang fotografer adalah dua hal yang berbeda, jika seorang fotografer cenderung mencari yang menarik, sebaliknya seorang pilot cenderung mencari suatu yang aman, sering waktu sesuatu yang menarik itu biasanya tidak aman, dan sebaliknya, kreativitas menjadi penjembatan akan dua hal tersebut, tidak hanya menjadi seorang pilot yang bertanggung jawab namun juga seniman yang bertanggung jawab.

Drone hanyalah sebuah alat, hal yang terpenting dan menjadi pembeda dalam sebuah karya adalah ide, maka dari itu hal utama yang harus dikembangkan adalah ideasional dan tentunya disusul oleh teknikal, yaitu kemampuan praksis dalam mewujudkan ide tersebut. Jangan takut untuk mencoba hal baru karena dari hal baru tersebut membuka peluang akan muncul ide-ide segar dalam penciptaan sebuah karya.

\section{KEPUSTAKAAN}

\section{Buku}

Arnheim, Rudolf. Art and Visual Perception: A Pshycology of The Creative Eye. California:University California Press, 1974.

Cheng, Eric. Aerial Photography and Videography Using Drones. San Francisco:Peachpit Press, 2016.

Davis, Harold. Creative Composition. Indianapolis:Wiley Publishing, 2010.

Dewan Kebudayaan Kota Yogyakarta. Menjadi Jogja. Yogyakarta:Dewan Kebudayaan Kota Yogyakarta. 2006. Freeman, Michael. The Photographer's Eye. Lewes:The Ilex Press, 2007.

Gebauer, Gunter \& Christoph Wulf. Mimesis: Culture, Art, Society. California:University of California Press, 1995.

Hawkes, Jason \& Adele McConnel. Aerial: The Art of Photography from The Sky. Mies: RotoVision, 2003.

Labastier, Simon. The Art and Craft of Montage. London: Mitchel Bezley ,1993.

Papilaya, Alex. Drone Foto dan Video. Jakarta: Gramedia Widyasarana Indonesia, 2015.

Raihanan, Hani. Negara di Persimpangan Jalan Kampusku. Yogyakarta: Kanisius, 2007.

Ruby, Jay. Picturing Culture: Exploraton of Film and Anthropology. Chicago:University of Chicago, 2000.

Sabdacarakatama, Ki. Sejarah Keraton Yogyakarta. Yogyakarta: Narasi, 2009. 
Simon, Steve. The Passionate Photographer. Jakarta: PT Elex Media Komputindo, 2011.

Soedjono, Soeprapto. Pot-Pourri Fotografi. Jakarta: Penerbit Universitas Trisakti, 2007.

Sumayku, Reynold. Pada Suatu Foto: Cerita dan Filosofi dalam Fotografi. Jakarta: Kaifa Publishing, 2016.

\section{Skripsi/artikel/jurnal}

Setiawan, Ade Dani. "Yogyakarta Dari Udara Sebagai Sumber Inspirasi Penciptaan Karya Seni Fotografi". Tugas Akhir Penciptaan FSMR ISI Yogyakarta: tidak diterbitkan. 1999

Stichelbaud,Birger (Ed.) et al. "Images of Conflict:Millitary Aerial Photography and Archeology". Newcastle:Cambridge Scholar Publishing, 2009.

\section{Pustaka laman}

Deluze, Gilles \& Rosalind Krauss. Plato and The Simulacrum.Cambridge:The MIT Press, 1983.(diakses pada 20 Maret 2017, pukul 18.00 WIB) http://introtodh2016.web.unc.edu/ files / 2016/11/Deleuze_Plato-andthe-Simulacrum.pdf

Schauble, Oren., Sollenberger, Roger. Using Drones for Aerial Photography. Berkeley:3DR, 2016. (diakses pada 16 Januari 2017, pukul 12:51 WIB) https://www.dropbox. com / sh / wqdq2ustmpthg6p/ 